\title{
Immunogenicity of Polysaccharides from Type III, Group B Streptococcus
}

\author{
Carol J. Baker and Morven S. Edwards, Departments of Pediatrics, \\ Microbiology, and Immunology, Baylor College of Medicine, \\ Houston, Texas 77030 \\ DeNNIS L. KASPER, Channing Laboratory and the Department of Medicine, \\ Peter Bent Brigham Hospital, Division of the Affiliated Hospitals Center, \\ Inc., Boston, Massachusetts 02115
}

\begin{abstract}
A B S T RA C T The immunogenicity and safety of two polysaccharides isolated from type III, group B Streptococcus, were tested in adults selected for existing low concentrations of natural antibody to the capsular polysaccharide of this organism. Both vaccine preparations (trichloroacetic acid and EDTA) were found to lack pyrogenicity and toxicity for experimental animals. A single 50- $\mathrm{gg}$ subcutaneous injection of either polysaccharide in human subjects elicited significant increases in antibody concentration in immunized compared with control individuals receiving phosphate-buffered saline. Antibody responses were maximal by $2 \mathrm{wk}$ and remained at $21 \mathrm{wk}$ after immunization. Vaccine-induced antibody was primarily of the IgG class. Of the two vaccines, the larger molecular size polysaccharide was significantly more immunogenic. Although no systemic reactions were recorded, mild transient local reactions occurred in $45 \%$ of vaccinees.
\end{abstract}

\section{INTRODUCTION}

The importance of the group B Streptococcus as a cause of serious and often fatal infection among neonates and young infants is well established $(1,2)$. Among isolates from these patients, $\cong 60 \%$ will be serologically classified as type III $(3,4)$. The antibody directed against the capsular polysaccharide of type III strains has been shown to be bactericidal in the presence of human polymorphonuclear leuko-

Dr. Edwards is the recipient of the Eleanor Clay Ford Fellowship from the Venereal Disease Research Fund of the American Social Health Association. Dr. Kasper is the recipient of Research Grant Career Development Award 1 KO4 AI 00126 from the National Institute of Allergy and Infectious Diseases.

Received for publication 3 January 1978. cytes and complement as determined by an opsonophagocytic assay (5). This same antibody has been detected by means of a quantitative radioactive antigen-binding assay in convalescent sera of patients recovering from type III, group B streptococcal disease (6). Our previous studies have shown a statistically significant correlation between risk for the development of invasive infant disease with type III strains and low concentration of maternal serum antibody to the type III capsular polysaccharide $(6,7)$. The antibody directed against the capsular polysaccharide of type III strains is present in high concentration in the sera of many pregnant women, and is transplacentally transferred to the neonate in most circumstances $(6,7)$. It has been our hypothesis that the correlation between low concentration of maternal antibody and risk for infant disease may provide an immunologic basis for prevention of infection due to type III strains by immunization. If a capsular polysaccharide isolated from type III, group B Streptococcus, were shown to be antigenic and safe in adults, perhaps immunization of adult women would be an effective means of preventing infant disease by transplacental passage of antibody. This maternal antibody might be protective during that period of time associated with infant susceptibility (i.e. the first 3 mo of life). Large molecular weight polysaccharides have been isolated from type III, group B Streptococcus and purified (8). ${ }^{1}$ The present study was designed to assess the immunogenicity of these preparations in those adult human volunteers most likely to benefit from immunizationthose with low concentrations of serum antibody.

\footnotetext{
${ }^{1}$ Kasper, D. L., D. K. Goroff, and C. J. Baker. Immunochemical characterization of native polysaccharides from group B Streptococcus: the relationship of the type III and group B determinants. Manuscript in preparation.
} 


\section{METHODS}

Vaccine. Polysaccharide antigens were extracted from one lot of type III group B Streptococcus (strain M732) grown in Todd-Hewitt broth (Difco Laboratories, Detroit, Mich.) supplemented with glucose (9). A 300-1 lot of organisms were grown in a fermenter (courtesy of Dr. John Robbins, Bureau of Biologics, Bethesda, Md.) with no attempt to maintain $\mathrm{pH}$ at neutrality. The pelleted organisms were washed with a neutral buffer-EDTA solution, centrifuged, and then the supernatant EDTA-antigen-containing solution was purified by alcohol fractionation, enzyme treatments, and gel filtration (EDTA non-pH-titrated antigen) (8). ${ }^{1}$ The EDTAwashed organisms were then reextracted with $10 \%$ cold trichloroacetic acid (TCA antigen), and the supernate was neutralized and purified as above. These antigens have been shown to be pure polysaccharides consisting of galactose, glucosamine, glucose, sialic acid, and another sugar which may be a heptose. ${ }^{1}$ The EDTA non-pH - titrated and TCA antigens have molecular sizes of 600,000 and 500,000 daltons, respectively. Both are acidic polysaccharides which demonstrate type III and group B serologic specificity. ${ }^{1}$ These two polysaccharide vaccines were suspended in pyrogen-free phosphate-buffered saline (PBS) ${ }^{2}$ at $100 \mu \mathrm{g} / \mathrm{ml}$ and stored at $4^{\circ} \mathrm{C}$. Sterility of these polysaccharides prepared for human use was tested in bulk before final packaging, and in $10 \%$ of the final packaged material in accordance with the regulations of the Food and Drug Administration (title 21, Sect. $\$ 610.12$ ). The PBS employed for suspension of the polysaccharides was packaged in an identical vial for use as placebo (PBS).

Animal toxicity studies. The general safety test employing guinea pigs (title 21 , Sect. $\$ 610.11$ ) was performed in $375-\mathrm{g}$ Hartley strain guinea pigs injected intraperitoneally with $500 \mu \mathrm{g}$ of each polysaccharide in $5 \mathrm{ml}$ of PBS. The animals were observed, weighed, and had their temperatures recorded daily for 12 days. The pyrogenicity of the vaccines was tested in 3-kg New Zealand white rabbits (Sect. \$610.13); rectal temperatures were recorded before the booster and then hourly for $4 \mathrm{~h}$ after intravenous injection with $100 \mu \mathrm{g}$ of each polysaccharide. Systemic toxicity in rabbits was assessed after intravenous injection with a total of $500 \mu \mathrm{g}$ of each vaccine in 10 divided doses over a 3-wk period. Daily observations and weights were recorded for 21 days. Interference with the growth rate of $21-\mathrm{g}$ mice was evaluated after intraperitoneal injection with $500 \mu \mathrm{g}$ of each polysaccharide (Sect. \$610.11). Mice were weighed daily and observed for 12 days. $1012-$ kg Cynamolgous monkeys received $50 \mu \mathrm{g}$ subcutaneous injections of each vaccine preparation. A second $50-\mu \mathrm{g}$ injection was given 4 wk later. Animals were observed for local and systemic reactions for $72 \mathrm{~h}$ after each injection, and sera were collected from the rabbits and monkeys at $0,2,4$, and 8 wk after immunization.

Subjects. 150 normal healthy adult volunteers (largely laboratory personnel and physicians at Baylor College of Medicine) had sera tested to determine the concentration of antibody to type III capsular polysaccharide antigen. 33 subjects with a serum concentration $<2.0 \mu \mathrm{g} / \mathrm{ml}$ volunteered for immunization. These subjects gave signed informed consent for participation in the study at the time of immunization. The subjects were randomized into three "vaccine" groups (of 11 each) by age- and sex-matching, and coded vaccines or placebo were administered in a

\footnotetext{
${ }^{2}$ Abbreviation used in this paper: PBS, phosphate-buffered saline.
}

double-blind fashion. There were nine male and two female volunteers in each of the groups receiving immunization with TCA or EDTA vaccines with a mean age of 27 (range 24-34) and 26.3 (range 24-29) yr, respectively. Eight male and three female volunteers were given placebo (PBS). Their mean age was 26.7 yr (range 24-31). All subjects were bled immediately before, and at 2 and $4 \mathrm{wk}$ after immunization. The EDTA and TCA vaccinees were bled at 8 and 21 wk after immunization. A subcutaneous injection of $0.5 \mathrm{ml}(50 \mu \mathrm{g})$ of one of three coded vaccine preparations (EDTA, TCA, or PBS) were given to each volunteer in the deltoid region. Subjects were interviewed and examined 24 and $48 \mathrm{~h}$ after the injection, and their symptoms, as well as their local reactions and temperature, were recorded.

Serologic methods. Serum antibody to the capsular polysaccharide of type III, group B Streptococcus was quantitated by means of a radioactive antigen-binding assay $(6,7)$. Sera were separated and stored in $2-\mathrm{ml}$ aliquots at $-70^{\circ} \mathrm{C}$. Results of the antibody responses to immunization were expressed as the geometric mean antibody concentration for each group (micrograms of antibody protein per milliliter of serum). $2 \mathrm{ml}$ of selected subjects' sera collected at 2 and 8 wk after immunization with EDTA vaccine was fractionated and the immunoglobulins were purified (10). Fractions containing primarily IgG or IgM were each tested in the radioactive antigen-binding assay to determine the immunoglobulin class of vaccine-induced antibody.

Statistical methods. The geometric mean antibody concentrations and $95 \%$ confidence intervals were calculated for each group of subjects (11). Differences in the concentration of antibody in preimmunization and a 4-wk postimmunization sera for subjects in the EDTA and TCA vaccine groups compared to controls (PBS) and to each other were analyzed by the Wilcoxon rank sum test (12) because of the nonparameter distribution of the antibody data.

\section{RESULTS}

Animal studies. Five tests were performed to assay for the toxicity of the EDTA and TCA polysaccharide vaccines in laboratory animals. One test was designed to detect contamination with biologically active endotoxin, and the other four were general toxicity tests. Toxicity studies were performed on final packaged material which had passed the sterility test. No significant rises in temperature $\left(>0.5^{\circ} \mathrm{F}\right)$ were detected in rabbits indicating that these preparations contained no biologically active endotoxin. The general toxicity tests in mice, guinea pigs, rabbits, and primates revealed normal weight gain and no systemic symptoms when animals injected with vaccines were compared with controls (PBS). Neither polysaccharide was found to induce antibody formation in rabbits or primates.

Toxicity in human volunteers. No systemic reactions were observed in the 22 vaccinees or the 11 control subjects. Overall, mild local reactions were observed in 10 of $22(45 \%)$ vaccinees but in none of the placebo (PBS) group. Two (18.2\%) of the TCA and eight $(72.8 \%)$ of the EDTA vaccinees had local 
reactions. These consisted of small areas of erythema $(<3 \mathrm{~cm}$ diameter) or induration $(<1 \mathrm{~cm}$ diameter) which persisted for $48 \mathrm{~h}$. Mild local tenderness which resolved within $48 \mathrm{~h}$ was noted by six of the EDTA vaccinees, but in none of the other subjects.

Antibody response. The antibody response of subjects immunized with polysaccharides (EDTA or TCA) or receiving placebo (PBS) is summarized in Table $\mathrm{I}$. No significant differences between the preimmunization concentrations of antibody were detected in sera from the three groups of volunteers. 2 and $4 \mathrm{wk}$ after immunization with PBS, antibody concentration was unchanged in the sera from control subjects. However, 2 wk after the immunization, sera from TCAand EDTA-immunized volunteers had geometric mean antibody concentrations of 2.26 and $9.18 \mu \mathrm{g} / \mathrm{ml}$, respectively. The rises in antibody concentration 4 wk after immunization with the EDTA and TCA vaccines were highly significant when compared to the PBS control group by means of the Wilcoxon rank sum text $(P=<0.001)$ (12). Furthermore, the EDTA vaccine was a significantly better immunogen than the TCA vaccine $(P=<0.01)$.

To define the immunoglobulin class of vaccineinduced antibody, sera from selected vaccine recipients demonstrating high concentration of antibody in postimmunization sera were fractionated. IgG was found to be the immunoglobulin accounting for the majority of antigen-binding in sera from these selected vaccinees at 2 and $8 \mathrm{wk}$ after immunization. That vaccine-induced antibody was primarily of the IgG class was further substantiated by the persistence of antibody in sera at similar concentrations $21 \mathrm{wk}$ after immunization.

\section{DISCUSSION}

Infant disease due to group B Streptococcus is observed during the first $2-3$ mo of life; the majority occurs at $<7$ days of age. This age is one during which transplacentally acquired maternal antibody, if present, protects young infants against a number of serious bacterial infections including disease due to type III, group B Streptococcus (6). Although polysaccharide vaccines have been shown to be relatively poor immunogens in infants, they are generally immunogenic in adults. Therefore, immunization of women with polysaccharides from group B Streptococcus offers the theoretical advantage of preventing disease in neonates and young infants by transplacental passage of antibody.

We have assessed the safety and antigenicity of two relatively large molecular size polysaccharides extracted by different methods from a type III strain of group B Streptococcus. One polysaccharide was extracted by washing cells grown in Todd-Hewitt broth supplemented with glucose with neutral bufferEDTA solution. After purification, this EDTA-III polysaccharide had a molecular size of 600,000 daltons. The second polysaccharide (TCA-III) was isolated from EDTA-washed cells by extraction with cold $10 \%$ TCA, and after purification it had a molecular size of 500,000 daltons. Both preparations were nontoxic in laboratory animals, and no untoward systemic reactions were observed in human volunteers. Local reactions were detected primarily in the EDTA vaccinees. These were mild, of short duration, and were similar to those which have been reported for several other bacterial polysaccharide vaccines.

The EDTA-III polysaccharide possessed significantly greater immunogenicity than the TCA-III vaccine as indicated by the number of subjects responding to immunization and the magnitude of their antibody response. This greater immunogenicity may be a reflection of the larger molecular size of the EDTA preparation. Size has been shown to be a crucial determinant of the immunogenicity of polysaccharides

TABLE I

Immunogenicity of TCA- and EDTA-Extracted Type III Polysaccharides

\begin{tabular}{lccccc}
\hline & \multicolumn{5}{c}{ Antibody concentration in $\begin{array}{c}\mu \mathrm{g} / \mathrm{ml} \text { - geometric mean } \\
\text { wk after immunization }\end{array}$} \\
\cline { 2 - 6 } Immunogen & 0 & 2 & 4 & 8 & 21 \\
\hline EDTA-III & 0.93 & 9.18 & 9.29 & 10.79 & 8.37 \\
& $(0.28-3.09)$ & $(0.14-603.5)$ & $(0.13-691.8)$ & $(0.12-794.3)$ & $(0.12-592.6)$ \\
TCA-III & 0.79 & 2.26 & 2.14 & 2.29 & 1.93 \\
& $(0.27-2.34)$ & $(0.04-95.5)$ & $(0.55-83.2)$ & $(0.05-104.7)$ & $(0.05-92.3)$ \\
PBS control & 0.79 & 0.80 & 0.79 & ND* & ND \\
& $(0.39-2.04)$ & $(0.39-1.58)$ & $(0.31-2.0)$ & ND & ND \\
\hline
\end{tabular}

* ND = not done. 
in man (13). Recently we purified an even larger molecular size type III polysaccharide $\left(1.0 \times 10^{6}\right.$ daltons) from organisms grown under more optimal growth conditions by maintaining a neutral $\mathrm{pH}$ throughout the growth cycle. ${ }^{1}$ Even greater immunogenicity might be expected when human volunteers are immunized with this more native EDTA-pH titrated polysaccharide.

Of the 11 human volunteers immunized with the EDTA type III polysaccharide, $8(72.7 \%)$ had $>1.0 \mu \mathrm{g} / \mathrm{ml}$ increases in serum antibody concentration at 2 wk after immunization, whereas only 4 TCA-III immunized volunteers of $11(36.4 \%)$ had $>1.0 \mu \mathrm{g} / \mathrm{ml}$ increases during the same interval. This rate of response to immunization with the EDTA polysaccharide is similar to that observed in adults receiving other polysaccharide vaccines when subjects were preselected for low concentration of serum antibody. For example, Anderson et al. (14) immunized 62 adults with polyribophosphate; of these, 32 had very low concentrations of antipolyribophosphate antibody in preimmunization sera and $23(71.9 \%)$ had $>1.0-\mu \mathrm{g} / \mathrm{ml}$ increases in antibody concentration detected $2 \mathrm{wk}$ after immunization. Similar results are recorded for group A meningococcal (15) and pneumococcal polysaccharides (16) in adults when response for subjects with low levels of antibody in preimmunization sera are analyzed separately. Since women with low concentrations of serum antibody to the capsular polysaccharide from type III, group B Streptococcus are those whose offspring are at risk for disease due to this microorganism $(6,7)$, the potential usefulness of an effective immunogen in this population requires evaluation. Although further studies are needed, the demonstration of the safety and immunogenicity of the EDTA-III polysaccharide in man represents the first step in realizing the prevention of group B streptococcal disease in neonates and young infants by immunologic methods.

\section{ACKNOWLEDGMENTS}

We are indebted to the members of the Pediatric Housestaff at Baylor College of Medicine for their willingness to volunteer for this study, and to Dr. George Grady, Dr. George Wright, and Ms. Leslie Wetterlow of the Massachusetts State Laboratory Institute for their assistance in the packaging, sterility, and animal toxicity testing of the vaccines. We gratefully acknowledge the skilled technical assistance of Bette J. Webb and Diana K. Goroff.

This work was supported by U. S. Public Health grants AI 13249 and AI 12381 from the National Institute of Allergy and Infectious Diseases.

\section{REFERENCES}

1. Baker, C. J. 1977. Summary of the workshop on perinatal infections due to group B Streptococcus. J. Infect. Dis. 136: 137-152.

2. Anthony, B. F., and D. M. Okada. 1977. The emergence of group B streptococci in infections of the newborn infant. Annu. Rev. Med. 28: 35.5-369.

3. Wilkinson, H. W., R. R. Facklam, and E. C. Wortham. 1973. Distribution by serologic type of group B streptococci isolated from a variety of clinical material over a five-year period (with special reference to neonatal sepsis and meningitis). Infect. Immun. 8: 228-235.

4. Baker, C. J., and F. F. Barrett. 1974. Group B streptococcal infections in infants: the importance of the various serotypes. J. Am. Med. Assoc. 230: 1158-1160.

5. Baltimore, R. S., D. L. Kasper, C. J. Baker, and D. K. Goroff. 1977. Antigenic specificity of opsonophagocytic antibodies in rabbit anti-sera to group B streptococci. J. Immunol. 118: 673-678.

6. Baker, C. J., D. L. Kasper, I. B. Tager, A. Paredes, S Alpert, W. M. McCormack, and D. K. Goroff. 1977. Quantitative determination of antibody to capsular polysaccharide in infection with type III strains of group B Streptococcus. J. Clin. Invest. 59: 810-818.

7. Baker, C. J., and D. L. Kasper. 1976. Correlation of maternal antibody deficiency with susceptibility to neonatal group B streptococcal infection. N. Engl. J. Med. 294: $752-756$.

8. Baker, C. J., D. L. Kasper, and C. E. Davis. 1976 Immunochemical characterization of the "native" type III polysaccharide of group B Streptococcus. J. Exp. Med. 143: $258-270$.

9. Baker, C. J., and D. L. Kasper. 1976. Microcapsule of type III strains of group B Streptococcus: production and morphology. Infect. Immun. 12: 189-204.

10. Rice, P. A., and D. L. Kasper. 1977. Characterization of gonococcal antigens responsible for induction of bactericidal antibody in disseminated infection. J. Clin. Invest. 60: 1149-1158.

11. Snedecor, G. W., and W. G. Cochran. 1967. Statistical Methods. Iowa State University Press. Ames, Iowa. 3-593.

12. Hollander, M., and D. A. Wolfe. 1973. Non-Parametric Statistical Methods. John Wiley \& Sons, Inc., New York. 503 pp.

13. Kabat, E. A., and A. E. Bezer. 1958. The effect of variation in molecular weight on the antigenicity of dextran in man. Arch. Biochem. Biophys. 78: 306-318.

14. Anderson, P., G. Peter, R. B. Johnston, Jr., L. H. Wetterlow, and D. H. Smith, 1972. Immunization of humans with polyribophosphate, the capsular antigen of Hemophilus influenzae, type b. J. Clin. Invest. 51: 39-44.

15. Artenstein, M. S., R. Gold, J. G. Zimmerly, F. A. Wyle, W. C. Branche, and C. Harkins. 1970. Cutaneous reactions and antibody response to meningococcal group $C$ polysaccharide vaccines in man. J. Infect. Dis. 121: $372-377$.

16. Heidelberger, M., C. M. MacLeod, and M. M. DiLapi. 1948. The human antibody response to simultaneous injection of six specific polysaccharides of pneumococcus. J. Exp. Med. 88: 369-373. 